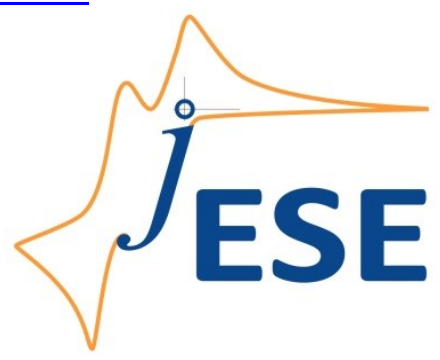

Open Access : : ISSN 1847-9286

www.jESE-online.org

Original scientific paper

\title{
Evaluation of strontium substituted lanthanum manganite- -based solid oxide fuel cell cathodes using cone-shaped electrodes and electrochemical impedance spectroscopy
}

\author{
Kent Kammer Hansen \\ Department of Energy Conversion and Storage, Technical University of Denmark, DK-4000 Roskilde, \\ Denmark \\ E-mail: kkha@dtu.dk
}

Received: February 3, 2018; Revised: February 27, 2018; Accepted: March 19, 2018

\begin{abstract}
Five $\mathrm{La}_{1-\mathrm{x}} \mathrm{Sr}_{x} \mathrm{MnO}_{3+\delta}$-based perovskites ( $x=0,0.05,0.15,0.25$ and 0.50 ) were synthesized and investigated by powder $X R D$, dilatometry and electrochemical impedance spectroscopy measurements and cone-shaped electrode techniques. The thermal expansion coefficient increased with increasing strontium content. It was shown that the total polarization resistance was the lowest for the intermediate compound, $L_{0.95} S_{0.05} \mathrm{MnO}_{3+\delta}$. Two arcs were found in the impedance spectra. These arcs were attributed to two one-electron processes. The results indicate that either $\mathrm{Mn}(\mathrm{III})$ is the catalytically active species or that the redox capacity is important for the activity of the compounds towards the reduction of oxygen in a solid oxide fuel cell. At higher temperatures, the oxide ionic conductivity may also play a role.
\end{abstract}

\section{Keywords}

LSM; EIS; Oxygen; SOFC; Cathode

\section{Introduction}

A solid oxide fuel cell (SOFC) is a high-temperature unit, which converts chemical energy directly into electricity and heat. The choice for a cathode is a LSM and YSZ (LSM = strontium-substituted lanthanum manganite and YSZ = yttria-stabilized zirconia) composite cathode [1]. Many studies of the activity of manganite-based perovskite electrodes towards the electrochemical reduction of oxygen have been undertaken in the literature, see i.e [2] for a review. There is insufficient agreement in the literature. Hammouche et al. [3] found that the activity towards the reduction of oxygen increased with an increasing amount of strontium, at least until the strontium content reached $50 \%$, using point electrodes at $960^{\circ} \mathrm{C}$. This finding was later confirmed by Hansen et al. [4] at a somewhat lower temperature of $500^{\circ} \mathrm{C}$. In contrast, Yasamoto et al. [5] found that the activity of LSM10 was much 
higher than the activity of LSM40, using porous planer electrodes. In a later publication, Hansen [6] showed that at temperatures of $400{ }^{\circ} \mathrm{C}$ or less, a less clear dependence on the composition existed. This study employed a combined cone-shaped electrode and electrochemical impedance spectroscopy (EIS) measurements of LSMx $\left(\mathrm{La}_{1-x} \mathrm{Sr}_{x} \mathrm{MnO}_{3+\delta}\right)$-based perovskite SOFC cathodes. The use of cone-shaped electrodes was first suggested by Fabry and Kleitz [7]. Cone-shaped electrodes are a useful technique when comparing different electrode materials [3,8-20]. There are several reasons for this. When using porous electrodes, the performance depends strongly on the microstructure. Also, the electrode is often mixed with electrolyte, itinerating the true properties of the electrode material. In addition to this, the electrode and electrode is sintered together during processing, leading to reaction between the electrode and the electrolyte. For cone-shaped electrodes the dependence on microstructure is less, it is not mixed with electrolyte and the electrode and electrolyte is sintered separately. In addition to the electrochemical properties, the thermal expansion coefficient was determined. In this study we for the first time report the detailed correlation between impedance data and the composition of LSM.

\section{Experimental}

The synthesis of the LSM-based perovskites was performed using a glycine-nitrate process [21]. In short, aqueous solutions of the metal-nitrates were mixed in the appropriate ratio in a beaker, before glycine was added. The mixtures were then heated on a hot plate until combustion. The resulting powders were then transferred to alumina crucibles, and the powders were calcined at $1100{ }^{\circ} \mathrm{C} / 12 \mathrm{~h}$ in air in a box furnace. The metal-nitrates used were the following: $\mathrm{La}\left(\mathrm{NO}_{3}\right)_{3} \cdot 6 \mathrm{H}_{2} \mathrm{O}(\mathrm{Alfa}$ Aesar, $99.9 \%$ ), $\mathrm{Sr}\left(\mathrm{NO}_{3}\right)_{2}$ (Alfa Aesar, $99 \%$ ), and $\mathrm{Mn}\left(\mathrm{NO}_{3}\right)_{2} \cdot 4 \mathrm{H}_{2} \mathrm{O}$ (Alfa Aesar, $99.98 \%$ ). The phase purity of the LSM perovskites was checked using powder X-ray diffraction using a Stoe theta-theta diffractometer equipped with CuK $\alpha$ radiation. The diffractograms were recorded in the interval $2 \theta$ : 20 to $80^{\circ}$. The cone-shaped electrodes were made by pressing 7-8 $\mathrm{g}$ of the powder in a die with a diameter of $10 \mathrm{~mm}$. The resulting cylinders were then sintered at $1250{ }^{\circ} \mathrm{C}$ for $12 \mathrm{~h}$ in air in a box furnace. Finally, the sintered cylinders were machined into cone-shaped electrodes. The electrochemical measurements were conducted as follows. The cone-shaped electrodes were equilibrated at temperature for $24 \mathrm{~h}$ before the EIS measurements. The measurements were performed at temperatures of 800,700 and $600{ }^{\circ} \mathrm{C}$ in the given order. For the EIS measurements, a Solartron 1260 in standalone mode was used. The frequency ranged from $1 \mathrm{MHz}$ to $0.05 \mathrm{~Hz}$ (or to $0.01 \mathrm{~Hz}$ at $600{ }^{\circ} \mathrm{C}$ ) with five points measured per decade. An amplitude of $24 \mathrm{mV}$ was used throughout. A pellet of $\mathrm{Ce}_{0.9} \mathrm{Gd}_{0.1} \mathrm{O}_{1.95}$ was used as the electrolyte. The pellet was polished with a 1 $\mu \mathrm{m}$ diamond paste. The contact areas of the cone-shaped electrodes were calculated using Newman's formula [22]:

$$
r=\frac{1}{4 \sigma R_{\mathrm{s}}}
$$

where $r$ is the radius of the contact point, $\sigma$ is the specific conductivity of the electrolyte and $R_{\mathrm{s}}$ is the intercept at high frequency in the impedance plot. The EIS data were fitting using a program by Boukamp [23]. In general, the EIS data could be fitted using two (RQ)'s in series with a series resistance. $Q$ is a constant phase element with the admittance:

$$
Y=Y_{0}\left(\mathrm{j} \omega / \omega_{0}\right)^{n}
$$

where $Y_{0}$ and $n$ are constants found from the fitting and $\omega$ is the angular frequency. At first, the $n$-values were allowed to vary freely. Then, the average of the $n$-values was estimated, and the fitting was repeated with a constant $n$. 


\section{Results}

The results from powder XRD are shown in Table 1 . All the manganite-based perovskite compounds are phase pure and belong to the hexagonal crystal system.

An example of an impedance spectrum is depicted in Figure 1. The electrochemical behavior of the manganite depends strongly on the amount of strontium, and the most active perovskite is the intermediate compound with $\mathrm{x}$ in $\mathrm{La}_{1-\mathrm{x}} \mathrm{Sr}_{\mathrm{x}} \mathrm{MnO}_{3+\mathrm{d}}$ equal to 0.05 , as seen in Figure 2 . The thermal expansion coefficient (TEC) is given in Table 2 . The TEC increases with increasing strontium content. In Table 3, the results from the fitting can be found. It is seen that the magnitude of the arcs is strongly dependent on the composition of the manganite. Table 4 gives the impedance of the individual arcs at $600^{\circ} \mathrm{C}$. The low frequency is the most dominant for all the compositions. In Table 5 the near equivalent capacities for two arcs at $600{ }^{\circ} \mathrm{C}$ are listed. The high frequency arc is seen to vary a lot with composition, whereas the low frequency arc is almost constant with composition. The last Table, Table 6, gives the contribution from the two arcs at $800^{\circ} \mathrm{C}$. As is the case at $600{ }^{\circ} \mathrm{C}$ the low frequency arc has the highest values.

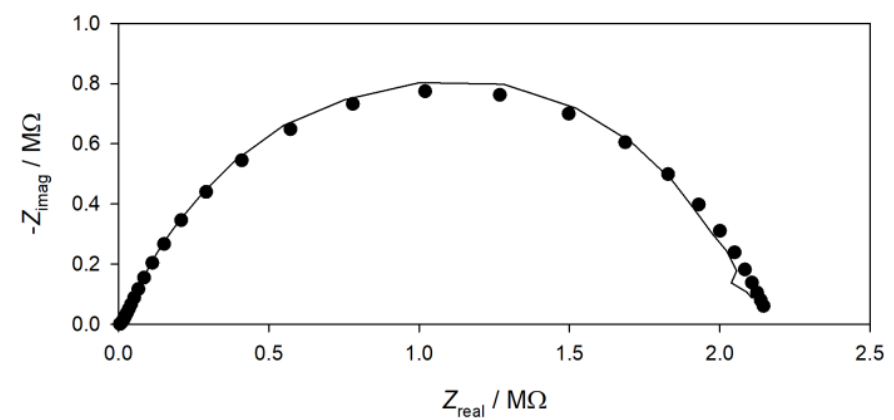

Figure 1. An example of an EIS spectrum for LSM5 at $600{ }^{\circ} \mathrm{C}$. The dots are the measured data, and the solid line is the fitted data.

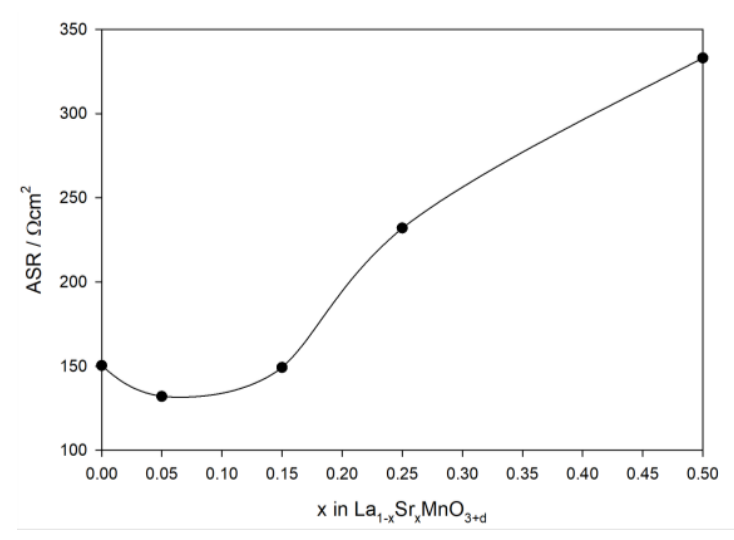

Figure 2. Total $A S R$ values as a function of $x$ in the LSMx compounds at $600^{\circ} \mathrm{C}$. The total ASR is lowest for the intermediate compound LSM5

Table 1. Unit cell parameters of the manganites. All the manganites belong to the hexagonal crystal system.

\begin{tabular}{cccccc}
\hline & LSM0 & LSM5 & LSM15 & LSM25 & LSM50 \\
\hline$a / \AA$ & 5.5197 & 5.5172 & 5.5128 & 5.4862 & 5.4440 \\
\hline$c / \AA$ & 13.354 & 13.342 & 13.358 & 13.569 & 13.424 \\
\hline
\end{tabular}

Table 2. TEC values recorded from room temperature to $1000^{\circ} \mathrm{C}$

\begin{tabular}{cccccc}
\hline & LSM0 & LSM5 & LSM15 & LSM25 & LSM50 \\
\hline TEC, $10^{-6} \mathrm{~K}^{-1}$ & 9.53 & 11.87 & 12.97 & 13.68 & 14.38 \\
\hline
\end{tabular}

Table 3. Total ASR values at the three different temperatures covered

\begin{tabular}{cccccc}
\hline \multicolumn{5}{c}{ ASR; $\Omega \mathrm{cm}^{2}$} \\
\hline$t /{ }^{\circ} \mathrm{C}$ & LSM0 & LSM5 & LSM15 & LSM25 & LSM50 \\
\hline 600 & 150.3 & 132.0 & 142.9 & 232.9 & 333.3 \\
\hline 700 & 48.5 & 16.1 & 29.0 & 37.1 & 37.8 \\
\hline 800 & 14.0 & 1.06 & 6.45 & 5.71 & 4.83 \\
\hline
\end{tabular}

Table 4. ASR values of the individual arcs at $600^{\circ} \mathrm{C} . R_{1}$ is high frequency arc and $R_{2}$ is low frequency arc

\begin{tabular}{cccccc}
\hline & \multicolumn{5}{c}{ ASR; $\Omega \mathrm{cm}^{2}$} \\
\cline { 2 - 6 } & LSM0 & LSM5 & LSM15 & LSM25 & LSM50 \\
\hline$R_{1}$ & 2.66 & 6.78 & 6.24 & 13.95 & 64.26 \\
\hline$R_{2}$ & 148.7 & 125.2 & 136.7 & 218.9 & 222.2 \\
\hline
\end{tabular}


Table 5. Near-equivalent capacitances for the individual arcs per unit area at $600^{\circ} \mathrm{C} . \mathrm{C}_{1}$ is high frequency arc and $C_{2}$ is low frequency arc

\begin{tabular}{cccccc}
\hline \multicolumn{5}{c}{$C_{\omega} / \mu \mathrm{F} \mathrm{cm}{ }^{-2}$} \\
\hline$C_{1}$ & LSM0 & LSM5 & LSM15 & LSM25 & LSM50 \\
\hline$C_{2}$ & 12.6 & 2500 & 26.7 & 350 & 17.5 \\
\hline
\end{tabular}

Table 6. ASR values of the individual arcs at $800^{\circ} \mathrm{C} . R_{1}$ is high frequency arc and $R_{2}$ is low frequency arc

\begin{tabular}{cccccc}
\hline & \multicolumn{5}{c}{ ASR; $\Omega \mathrm{cm}^{2}$} \\
\cline { 2 - 6 } & LSM0 & LSM5 & LSM15 & LSM25 & LSM50 \\
\hline$R_{1}$ & 0.13 & 0.22 & 0.25 & 0.09 & 0.48 \\
\hline$R_{2}$ & 13.9 & 2.26 & 6.40 & 5.54 & 4.28 \\
\hline
\end{tabular}

\section{Discussion}

The XRD results agree with the literature, that is, all the manganites belongs to the hexagonal crystal system [24]. That the TEC increases with $\mathrm{Sr}$ content is expected as $\mathrm{Sr}$ (II) has approximately $2 / 3$ of the bonding energy of La(III).

The magnitude of the ASR is very high on the cone-shaped electrodes compared to that of the porous composite electrodes of the same materials $[8,25]$. This finding is partly because the coneshaped electrodes not are composite electrodes, and partly due to the interface between the electrode-electrolyte, which not is optimized in the case of the cone-shaped electrodes. The geometrical configuration of the cone-shaped electrode limits the number of contact points at the electrode/electrolyte interface. Additionally, the cone-shaped electrode is dense and therefore has a low surface area.

For mixed conducting perovskite-based electrodes a three-step mechanism has been proposed [26]. This mechanism includes a slow redox reaction at the surface of the electrodes, the diffuseion of oxide anions through the bulk of the electrodes and the transport of oxide anions across the electrode-electrolyte interface. At $600^{\circ} \mathrm{C}$ the oxide ionic conductivity of the LSM-based perovskites is very low, and they are not considered to be mixed conductors $[27,28]$. However, a simple mechanism has been suggested for pure electronic conductors that can explain the two-arc impedance spectrum. The mechanism has been suggested by van Hessel et al. [29,30] for a gold electrode and by Divisek et al. for LSM30 [31]. The mechanism is given below using Kröger-Vink notation.

$$
\begin{aligned}
& 1 / 2 \mathrm{O}_{2}(\mathrm{~g})+\mathrm{ad} \rightarrow \mathrm{O}_{\mathrm{ad}} \\
& \mathrm{O}_{\mathrm{ad}}+\mathrm{e}^{\prime} \rightarrow \mathrm{O}_{\mathrm{ad}}^{-} \\
& \mathrm{O}_{\mathrm{ad}}^{-}+\mathrm{V}_{\mathrm{O}}^{\cdot \bullet}+\mathrm{e}^{\prime} \rightarrow \mathrm{O}_{\mathrm{O}}^{\mathrm{x}}+\mathrm{ad}
\end{aligned}
$$

where $V_{0}^{*}$ is a vacancy in the electrolyte, $O_{0}^{x}$ is an oxide anion in the electrolyte and ad is an adsorption site on the surface of the electrode. It is seen that this mechanism includes two oneelectron transfer reactions. If one arc is the result of the transport of oxide anions across the electrode-electrolyte interface, then the double layer capacity of this arc should be in the range of $10^{-6}$ to $10^{-4} \mathrm{~F} \mathrm{~cm}^{-2}[27]$. The near-equivalent capacitance of a constant phase element in parallel with a resistance can be calculated from the equation [32]:

$$
C_{\omega}=R^{(1-n) / n} Y_{0}^{1 / n}
$$

where $R$ is the resistance and $Y_{0}$ and $n$ are constants. All three values are found from the fitting. As seen from Table 4, the values of the near-equivalent capacity for the high-frequency arc is almost within the values predicted for a double layer capacity, suggesting that the high-frequency arc is due to the transport of oxide anions across the electrode-electrolyte interface. The magnitude of 
the high-frequency arc is seen to increase with increasing strontium content. This strong dependence on composition indicates that the catalytic properties of the electrode material are also important for the magnitude of the high-frequency arc. This finding again indicates that the highfrequency arc not only is due to a simple transport of oxide anions across the electrode-electrolyte interface, as suggested by Siebert et al. [26], but also includes the transference of electrons, as predicted by the mechanism suggested by van Hessel et al. [29,30] and Divisek et al. [31].

The low-frequency arc is then, accordingly to the mechanism, due to the transference of one electron from the electrode to an adsorbed oxygen atom. This step can be described as a slow redox reaction at the surface of the electrode. The values found in Table 4 are in good agreement with the capacitance found for a surface reaction.

The amount of $\mathrm{Mn}(\mathrm{III})$ and the redox capacity decrease with increasing strontium content, and the activity of the manganite-based cathodes decreases with increasing strontium content. This result indicates that one of these two parameters is important for the activity of the manganites towards the electrochemical reduction of oxygen. The two one-electron processes can explain why the magnitude of both arcs depends on the strontium content. The greater activity of LSM5 compared with that of LSMO indicates that the amount of oxide ion vacancies is important for the activity of the manganites towards the electrochemical reduction of oxygen.

The trend found in this study for the manganites at $600{ }^{\circ} \mathrm{C}$ follows the trend found for the ferrites [33]. This finding also indicates that $\mathrm{Mn}(\mathrm{III})$ is the catalytically active species in manganites, just as Fe(III) is the catalytically active species in ferrites [33].

At $800{ }^{\circ} \mathrm{C}$ the picture changes, as it is seen that the activity towards the reduction of oxygen increases with increasing strontium content, except for LSM5. At $800^{\circ} \mathrm{C}$, the oxide ionic conductivity of the manganites is higher than the conductivity at $600{ }^{\circ} \mathrm{C}$, and this may explain why a change in the order is observed at $800^{\circ} \mathrm{C}$, as the ionic conductivity of the manganites increase with increasing strontium content [27]. However, it must be said that the differences in the total ASR among LSM15, LSM 25 and LSM50 are very small.

The results at $600^{\circ} \mathrm{C}$ presented in this work confirm the findings by Yasamoto et al. [4]. However, the results reported by Hammouche et al. [2] were obtained at higher temperature $\left(960^{\circ} \mathrm{C}\right)$, and it is seen that the values reported in this study at $800^{\circ} \mathrm{C}$ follow the trend reported by Hammouche et al. [2] except for LSM5, which not was studied by Hammouche et al. [2]. Some discrepancies with earlier studies are observed. These discrepancies can be due to the sluggishness of the reactions at low temperatures compared to that at a high temperature and the different pretreatments of the electrodes before recording the impedance spectroscopy or cyclic voltammetry measurements. Additionally, the EIS was conducted at OCV, whereas the cyclic voltammetry data were recorded far from the OCV.

\section{Conclusion}

The activity of LSM-based perovskite cathodes are determined mainly by the amount of Mn(III) or perhaps the redox capacity. The amount of oxide ion vacancies might also be important. The intermediate compound LSM5 has the highest activity towards the reduction of oxygen in an SOFC. The reduction of oxygen is suggested to take place via two one-electron processes.

Acknowledgments: Our colleagues at the Department of Energy Conversion and Storage are thanked for fruitful discussions. The financial support from Energinet.dk through PSO-R\&D-project no. 2006-1-6493 is gratefully acknowledged. 


\section{References}

[1] N. Q. Minh, T. Takahashi, Science and technology of ceramic fuel cells, Elsevier Science B.V. (1995).

[2] S. P. Jiang, Journal of Materials Science 43 (2008) 6799-6833.

[3] A. Hammouche, E. Siebert, A. Hammou, Materials Research Bulletin 24 (1989) 367-380.

[4] K. Kammer Hansen, H. Christensen, E. M. Skou, Ionics 6 (2000) 340-345.

[5] K. Yasumoto, M. Shiono, H. Tagawa, M. Dokiya, K. Hirano, J. Mizusaki, Journal of the Electrochemical Society 149 (2002) A531-A536.

[6] K. Kammer Hansen, Materials Research Bulletin 48 (2013) 3274-3277.

[7] P. Fabry, M Kleitz, Journal of Electroanalytical Chemistry 57 (1974) 165-177.

[8] T. Jacobsen, B. Zachau-Christiansen, L. Bay, M. J. Jorgensen, Electrochimica Acta 46 (2001) 1019-1024.

[9] K. K. Hansen, M. Søgaard, M. Mogensen, Electrochemical and Solid-State Letters 10 (2007) B119-B121.

[10] V. L. E. Simonsen, D. Find, M. Lilliedal, R. Petersen, K. Kammer, Topics in Catalysis 45 (2007) 143-148.

[11] K. K. Hansen, Electrochemistry Communications 9 (2007) 2721-2724.

[12] K. K. Hansen, Journal of Applied Electrochemistry 38 (2008) 591-595.

[13] V. L. E. Simonsen, Linda Nørskov, K. Kammer Hansen, Journal of Solid State Electrochemistry 12 (2008) 1573-1577.

[14] F. Bræstrup, K. K. Hansen, Journal of Solid State Electrochemistry 13 (2009) 1241-1250.

[15] [15] K. Kammer Hansen, lonics, 15 (2009) 325-328.

[16] V. L. E. Simonsen, L. Nørskov, A. Hagen, K. Kammer Hansen, Journal of Solid State Electrochemistry 13 (2009) 1529-1534.

[17] K. Kammer Hansen, Journal of the Electrochemical Society 156 (2009) B1257-B1260.

[18] F. Bræstrup, K. K. Hansen, Journal of Applied Electrochemistry 39 (2009) 2369-2374.

[19] F. Bræstrup, K. K. Hansen, Journal of Solid State Electrochemistry 14 (2010) 157-166.

[20] C. Graves, B. R. Sudireddy, M. Mogensen, ECS Transactions 28(11) (2010) 173-192

[21] L. A. Chick, L. R. Pederson, G. D. Maupin, J. L. Bates, L. E. Thomas, G. J. Exarhos, Materials Letters 10 (1990) 6-12.

[22] J. Newman, Journal of the Electrochemical Society 113 (1966) 501-502.

[23] B. A. Boukamp, Solid State lonics 20 (1986) 31-44.

[24] I. G. Krogh Andersen, E. Krogh Andersen, P. Norby, E. Skou, Journal of Solid State Chemistry 113 (1994) 320-326.

[25] E. P. Murray, M. J. Sever, S. A. Barnett, Solid State lonics 148 (2002) 27-34.

[26] E. Siebert, A. Hammouche, M. Kleitz, Electrochimica Acta 40 (1995) 1741-1753.

[27] S. B. Adler, J. A. Lane, B. C. H. Steele, Journal of the Electrochemical Society 143 (1996) 3554-3564.

[28] S. Carter, A. Selcuk, R. J. Chater, J. Kajda, J. A. Kilner, B. C. H. Steele, Solid State lonics 53-56 (1992) 597-605.

[29] B. A. van Hessel, B. A. Boukamp, A. J. Burggraaf, Solid State lonics 48 (1991) 139-154.

[30] B. A. van Hessel, B. A. Boukamp, A. J. Burggraaf, Solid State lonics 48 (1991) 155-171.

[31] J. Divisek, J. W. Erning, R. Jung, B. Steffen, U. Stimming, K. Wippermann, in Proceedings of the $17^{\text {th }}$ International Symposium on Materials Science; High Temperature Electrochemistry: Ceramics and Metals, ed. F.W. Poulsen et al., Roskilde, Denmark, pp. 229-234 (1996).

[32] T. Jacobsen, B. Zachau-Christiansen, L. Bay, S. Skaarup, in Proceedings of the $17^{\text {th }}$ International Symposium on Materials Science; High Temperature Electrochemistry: Ceramics and Metals, ed. F.W. Poulsen et al., Roskilde, Denmark, pp. 29 (1996).

[33] K. Kammer Hansen, M. Mogensen, ECS Transactions, 13 (2008) 153-160

(C)2018 by the authors; licensee IAPC, Zagreb, Croatia. This article is an open-access article distributed under the terms and conditions of the Creative Commons Attribution license (http://creativecommons.org/licenses/by/4.0/) 